\section{Effects of an elevated position on time to tracheal intubation by novice intubators using Macintosh laryngoscopy or videolaryngoscopy: randomized crossover trial}

\author{
Abraham K. C. Wai, Colin A. Graham \\ Accident and Emergency Medicine Academic Unit, The Chinese University of Hong Kong, Shatin, Hong Kong
}

Objective To investigate the time to tracheal intubation using Glidescope videolaryngoscopy (GVL) compared to that of standard laryngoscopy, by using a Macintosh blade (SLM) in a human patient simulator in supine and elevated (ramped) positions.

Methods In this randomized crossover design, novice intubators (first-year medical students), using both laryngoscopic techniques, attempted tracheal intubation on a human patient simulator with a "normal airway" anatomy (Cormack-Lehane grade I). The simulator was placed in both supine and ramped positions using a commercial mattress system. The mean time to intubation and complications were compared between GVL and SLM in both positions. The percentage of glottic opening (POGO, GVL only) was estimated during intubation in the ramped and supine positions. The primary outcome was time to intubation, and the secondary outcomes included complication rates such as esophageal intubation and dental trauma.

Results There was no difference in the mean time to intubation in either position $(P=0.33)$. The SLM intubation was significantly faster than GVL (mean difference, 1.5 minutes; $P<0.001$ ). The mean POGO score for GVL improved by 8\% in the ramped position compared to that in supine position $(P=0.018)$. The esophageal intubation rate for SLM was $15 \%$ to $17 \%$ compared to $1.3 \%$ for GVL; dental trauma occurred in 53\% to 56\% of GVL, compared to 2\% to 6\% for SLM (P< 0.001 , respectively).

Conclusion Novices had shorter intubation times using standard laryngoscopy with a SLM compared to GVL in both supine and ramped positions. GVL resulted in fewer esophageal intubations, but more dental trauma than standard laryngoscopy.

Keywords Intubation; Laryngoscopy; Ramped position; Supine position; Tracheal

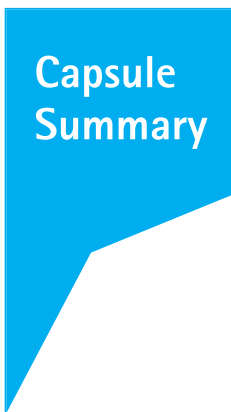

What is already known

Appropriate positioning of patient is an essential factor for successful endotracheal intubation. Ramping and videolaryngoscopy aid intubation process.

What is new in the current study

Position of patients did not affect the outcome in either direct laryngoscopy or videolaryngoscopy. Videolaryngoscopy was associated with better performance and less complications
eISSN: 2383-4625

Received: 8 May 2015

Revised: 12 July 2015

Accepted: 13 July 2015

Correspondence to: Colin A. Graham Accident and Emergency Medicine Academic Unit, The Chinese University of Hong Kong, Room 02C47, 2/F, Main Clinical Block and Trauma Centre, Prince of Wales Hospital, Shatin, New Territories, Hong Kong E-mail: cagraham@cuhk.edu.hk

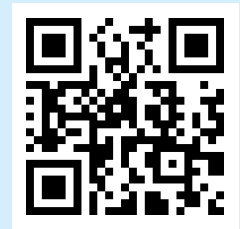

How to cite this article:

Wai AK, Graham CA. Effects of an elevated position on time to tracheal intubation by novice intubators using Macintosh laryngoscopy or videolaryngoscopy: randomized crossover trial. Clin Exp Emerg Med 2015;2(3):174-178.

This is an Open Access article distributed under the terms of the Creative Commons Attribution Non-Commercial License (http:// creativecommons.org/licenses/by-nc/3.0/). 


\section{INTRODUCTION}

Airway management is a core issue when dealing with critically ill patients. ${ }^{1-3}$ Establishing a definitive airway for these patients is often a paramount intervention in the emergency department; however, intubation can be complicated by several factors, ${ }^{4}$ including obesity. Obesity often makes basic airway support with a bag-valve-mask device difficult, and obese patients are prone to rapid desaturation owing to low functional residual capacity. ${ }^{5}$ Obesity is a major issue in developed countries, with an increasing prevalence. $^{6}$

The rapid airway management positioner (RAMP; Airpal, Center Valley, PA, USA) was designed to facilitate intubation by elevating the head and aligning the ear to the sternal notch in order to optimize the position for tracheal intubation.? The RAMP is a portable inflatable device powered by its own air supply that can be used in emergency settings. Regardless of body habitus, the RAMP can be quickly inflated and adjusted to provide the laryngoscopist with an improved view of the vocal cords. The device may also lengthen the apneic time period to critical hypoxia in morbidly obese patients by improving the ventilation-perfusion mismatch during preoxygenation.

In many emergency departments, junior medical staff is responsible for resuscitation cases. However, the inexperience of junior staff can lead to prolongation of the time to effective airway management, particularly for patients with difficult airways. Devices such as the Airpal RAMP and various videolaryngoscopes may facilitate more effective emergency tracheal intubation by junior medical staff. ${ }^{7-12}$ This study was thus designed to assess whether such a system could allow inexperienced junior staff to perform the procedure in less time and with few complications.

In this prospective randomized crossover study, we aimed to compare the time to intubation and the number of attempts required for successful intubation using both the Glidescope videolaryngoscope and the standard Macintosh laryngoscope in the normal and elevated (ramped) positions (using the RAMP device) and to compare the quality of laryngoscopic view (determined by the percentage of glottic opening [POGO] score) for the four different groups.

\section{METHODS}

\section{Participants}

The participants for this study were drawn from the cohort of first year undergraduate medical students from the Chinese University of Hong Kong. They were tested during the first 3 weeks of summer vacation at the end of their first year. All participants were informed that their performance would be evaluated and used for scientific study only. No personal data was collected.

\section{Ethical considerations}

The study protocol was approved by the local Clinical Research Ethics Committee and the Dean of the Faculty of Medicine approved participation of students. The study was conducted in accordance with the Declaration of Helsinki. None of the participants were prompted, coached, or prepared in any way prior to the study.

\section{Equipment}

The laryngoscopes used were the standard Macintosh laryngoscope (size 4 blade) and the Glidescope videolaryngoscope (adult size, equivalent to size 4; LMA Vertriebs- $\mathrm{GmbH}$, Windhagen, Germany). To standardize the cuff inflation volume, we used the recommended maximum volume. The manikin trachea was connected to a volumeter on which the tidal volume could be read after positioning the tracheal tube. The time from removal of the oxygen mask from the manikin's face to the first recorded ventilation through the tracheal tube was measured using a stopwatch.

A human patient simulator (Medical Education Technologies, Sarasota, FL, USA) was used as a manikin for insertion of the tracheal tubes. The human patient simulator was placed on a standard trolley with adjustable height and was therefore easily accessible. The same manikin was used for all intubation attempts. Having consulted an experienced anesthetist in the Faculty of Medicine on the difficulty of intubation of Hong Kong Chinese patients, we decided to keep the basic manikin settings.

\section{Protocol}

This was a prospective randomized crossover study with a $2 \times 2$ factorial design. As orotracheal intubation is taught in the final year of study; none of the first year medical students had had any relevant training or experience. All participants were shown a standard presentation in lecture format covering the anatomy of the airway, the clinical use of orotracheal intubation, an introduction of equipment, as well as a brief instructional video on laryngoscopy and orotracheal intubation. ${ }^{13}$ They were also briefed on how to estimate a the POGO score at laryngoscopy before the study began. Students were randomly allocated to the Glidescope laryngoscope first or Macintosh laryngoscope first groups. They were then randomly allocated to one of two possible sequences: (1) RAMP then normal position or (2) normal then RAMP position (Fig. 1). Before their attempts, the participants were briefed on the procedure and performed trial intubations in order to familiarize themselves with the procedure. They intubated from the 
end of the bed, behind the head of the manikin. All participants were allowed to adjust the height of the bed to facilitate the procedure.

Randomization was done by drawing lots. Students were then taken to the manikin (in the appropriate initial position) and asked to pass the tracheal tube, noting the POGO score on laryngoscopy for the Glidescope scenarios. The time taken for intubation was recorded to the nearest second using a stopwatch.

The study was conducted in the Clinical Simulation Centre of the Prince of Wales Hospital in Shatin, in collaboration with the Accident and Emergency Medicine Academic Unit and KCT Clinical Skills Learning Centre of the Chinese University of Hong Kong.

The primary outcome was the time to intubation, defined as the time (measured to the nearest second using a stopwatch) from taking the bag-valve-mask device off the manikin's face to the beginning of the first ventilation through a successfully placed tracheal tube. We did not censor the time to intubation, as we wanted to assess the true differences in techniques, rather than focusing on the immediate clinical consequences of potentially prolonged laryngoscopy.

The secondary outcome measures included POGO scores and

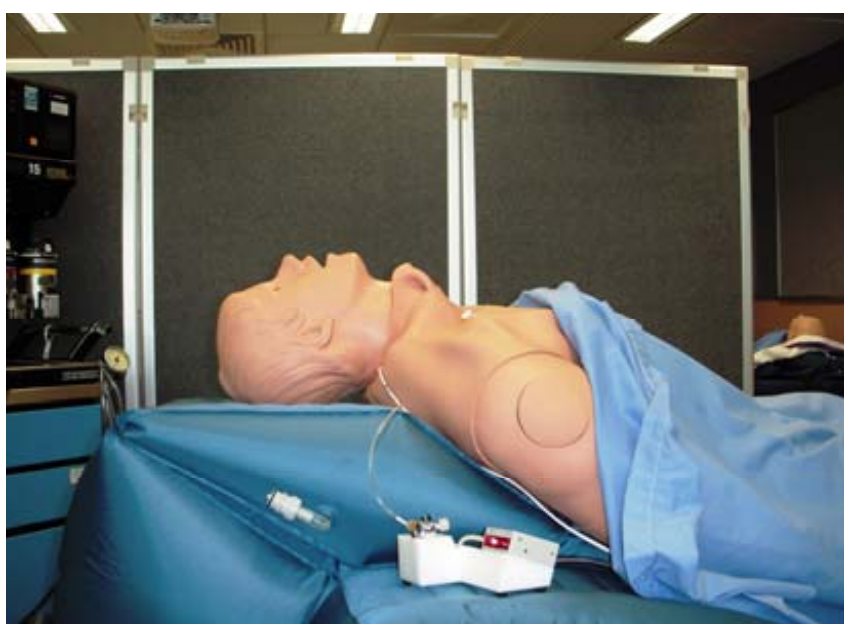

Fig. 1. The manikin in different postures. Ramped: a "sniffing" position, with head extension and flexion of the neck on the body. the incidence of intubation complications, including esophageal intubation and dental injuries. The independent sample t-test was used to analyze the time and POGO score results, whilst Fisher's exact test was used for categorical results. We show 95\% confidence intervals (Cls) where appropriate.

\section{RESULTS}

From the population of 120 first year students, 75 students volunteered to participate. A summary of the primary and secondary outcome measures is shown in Table 1 and Table 2.

In the supine position, intubation using the Macintosh laryngoscope was significantly faster than that using the videolaryngoscope with a mean difference of 1.67 minutes $(95 \% \mathrm{Cl}, 1.2$ to 2.1 minutes, $P<0.001)$. Similarly, in the ramped position, intubation using the Macintosh laryngoscope was significantly faster than that with the videolaryngoscope, with a mean difference of 1.44 minutes ( $95 \% \mathrm{Cl}, 1.0$ to 1.8 minutes, $\mathrm{P}<0.001)$.

Using the Macintosh laryngoscope, there was no significant difference between the supine position and the ramped position in terms of time to intubation (mean difference, 0.11 minutes; $95 \% \mathrm{Cl},-0.3$ to 0.5 minutes; $P=0.58$ ). Using the videolaryngoscope, there was no significant difference between the supine position and the ramped position in terms of time to intubation (mean difference, 0.34 minutes; $95 \% \mathrm{Cl}_{1}-0.1$ to 0.8 minutes; $\mathrm{P}=$ 0.14). The POGO score was not assessed for the Macintosh laryngoscope due to technical difficulties for obtaining a consistent view by both the participant and the assessor during the intubation process.

The view produced by videolaryngoscopy (mean POGO score) was $8 \%$ better in the ramped position than in the supine position $(P=0.018)$. In the supine position, the esophageal intubation rate for the Macintosh laryngoscope was $13 / 75$ compared to $1 / 75$ for the video laryngoscope $(P=0.001)$. In the ramped position, the esophageal intubation rate for the Macintosh laryngoscope was $11 / 75$ compared to $0 / 75$ for the video laryngoscope $(P<0.001)$.

Dental trauma occurred in 40 of 75 video laryngoscopies in the

Table 1. Primary and secondary outcomes in 4 groups

\begin{tabular}{|c|c|c|c|c|c|}
\hline & $\begin{array}{l}\text { Supine Macintosh } \\
\text { laryngoscope }\end{array}$ & $\begin{array}{c}\text { Supine Glidescope video } \\
\text { laryngoscope }\end{array}$ & $\begin{array}{l}\text { Ramped Macintosh } \\
\text { laryngoscope }\end{array}$ & $\begin{array}{l}\text { Ramped Glidescope video } \\
\text { laryngoscope }\end{array}$ & P-value \\
\hline $\begin{array}{l}\text { Mean time to intubation, min (mean, } \\
95 \% \mathrm{Cl} \text { ) }\end{array}$ & $1.13(0.85-1.41)$ & $2.80(2.48-3.12)$ & $1.03(0.77-1.29)$ & $2.46(2.15-2.78)$ & $<0.05$ \\
\hline Mean POGO score (mean, 95\% Cl) & - & $62.80(57.76-67.84)$ & - & $71.10(66.43-75.77)$ & $<0.05$ \\
\hline Esophageal intubations (n) & $13 / 75$ & $1 / 75$ & $11 / 75$ & $0 / 75$ & $<0.05$ \\
\hline Dental injuries (n) & $2 / 75$ & $40 / 75$ & $5 / 75$ & $42 / 75$ & $<0.05$ \\
\hline
\end{tabular}

Percentage of glottic opening scores were not determined for Macintosh laryngoscopy intubation attempts. POGO, percentage of glottic opening; $\mathrm{Cl}$, confidence interval. 
Table 2. Primary outcome according to position and equipment, separately

\begin{tabular}{lcccccc}
\hline & Supine & Ramped & P-value & Macintosh & Glidescope & P-value \\
\hline Mean time to intubation, $\min ($ mean, $95 \% \mathrm{Cl})$ & $1.97(1.72-2.22)$ & $1.75(1.52-1.98)$ & 0.33 & $1.08(0.90-1.26)$ & $2.63(2.40-2.86)$ & $<0.001$
\end{tabular}

$\mathrm{Cl}$, confidence interval.

supine position compared to 2/75 Macintosh laryngoscopies $(\mathrm{P}<$ 0.001 ), while in the ramped position, dental trauma occurred in 42 of 75 video laryngoscopies, compared to 5/75 Macintosh laryngoscopies $(\mathrm{P}<0.001)$. Position did not affect the rate of complications $(P=0.44)$.

\section{DISCUSSION}

Overall, use of the Macintosh laryngoscope led to faster times to intubation than the Glidescope videolaryngoscope. Given that our subjects were novice intubators, advanced hand-eye coordination would be required for the Glidescope compared to that required for the Macintosh scope, leading to the difference in intubation times. The elevated (ramped) position did not lead to shorter times for intubation than the supine position, for either laryngoscope. For the Glidescope, this was in spite of an improved laryngoscopic view in the ramped position; although the improvement was statistically significant, an $8 \%$ improvement in glottic view may not be a clinically significant difference. For example, the improvement of a grade II view to a grade I view is highly unlikely to improve the time to intubation; and yet an improvement from a grade IV to a grade III view may convert a nearly impossible intubation into a less difficult scenario. Given that, in our simulated scenario, the grade was set to grade I, this improvement in view is unlikely to have made any significant difference to the intubation times.

The fact that we did not find a difference in favor of the ramped position in this study should not be interpreted as a lack of effect; our group of subjects was comprised of novice intubators, performing the procedure for the first time. Experienced intubators may yield very different results, and other potential benefits of the ramped position for obese and overweight patients still hold (improvement of preoxygenation, prolongation of safe apnea time, improved functional residual capacity, etc.). Further study is required to delineate the exact role of the ramped position in the emergency department environment.

Esophageal intubations were much more common in the Macintosh laryngoscope group than in the Glidescope group. The major advantage of the Glidescope is that it is possible to watch the tube pass through the vocal cords under direct visual inspection, without moving the scope, and therefore esophageal intubation may be less likely. With a Macintosh laryngoscope, the view of the cords is obscured as the tube passes through them; it is possible that this loss of view leads to the increased frequency of esophageal intubation seen in our study. It is likely that, with practice, this rate would decrease over time; however, our findings indicate the absolute need for novice intubators to evaluate objectively the correct tracheal tube placement every time they perform an intubation.

Dental trauma was much more common in the Glidescope group. While the size and shape of the two devices are similar, it is possible that the intubator concentrated on the screen view when using the Glidescope to an extent that they neglected to ensure that the teeth are not injured. This was in contrast to the Macintosh, where the operator's focus remains on the mouth and oropharynx, which allows for careful intubation. Again, it is possible that with practice, the rate of dental trauma would decrease over time.

Overall, the Macintosh laryngoscope seems to be the best option for intubating patients in either supine or ramped position by novice intubators. Care must be taken to ensure that the trachea, rather than the esophagus, has been intubated correctly.

\section{CONFLICT OF INTEREST}

Airpal (Coopersburg, PA, USA) supplied the RAMP device evaluated in this study free of charge. We thank Dr Daniel Gabbay for providing this to us for evaluation. Dr Gabbay and Airpal had no involvement whatsoever in study design, statistical analysis or data interpretation.

\section{ACKNOWLEDGMENTS}

We thank Airpal for providing the RAMP device for evaluation. We thank the Kai Cheong Tong Foundation for their kind donation of the METI Human Patient Simulator to the Faculty of Medicine at Chinese University of Hong Kong which was used in this study. We thank Professor TF Fok, Former Dean of the Faculty of Medicine, for allowing us to enrol students from the Faculty of Medicine for this study. Finally, we thank our subjects, year 1 medical students of the Chinese University of Hong Kong for their willingness to participate. 


\section{REFERENCES}

1. Graham CA, Beard D, Oglesby $A J$, et al. Rapid sequence intubation in Scottish urban emergency departments. Emerg Med J 2003;20:3-5.

2. Graham CA, Beard D, Henry JM, McKeown DW. Rapid sequence intubation of trauma patients in Scotland. J Trauma 2004;56: 1123-6.

3. Oglesby AJ, Graham CA, Beard D, McKeown DW. Paediatric intubation in Scottish emergency departments. Paediatr Anaesth 2003;13:589-95.

4. Graham CA. Advanced airway management in the emergency department: what are the training and skills maintenance needs for UK emergency physicians? Emerg Med J 2004;21:14-9.

5. Altermatt FR, Munoz HR, Delfino AE, Cortinez LI. Pre-oxygenation in the obese patient: effects of position on tolerance to apnoea. Br J Anaesth 2005;95:706-9.

6. Yatsuya $\mathrm{H}, \mathrm{Li}$ Y, Hilawe EH, et al. Global trend in overweight and obesity and its association with cardiovascular disease incidence. Circ J 2014;78:2807-18.

7. Levitan RM, Mechem CC, Ochroch EA, Shofer FS, Hollander JE. Head-elevated laryngoscopy position: improving laryngeal exposure during laryngoscopy by increasing head elevation. Ann Emerg Med 2003;41:322-30.
8. Rabiner JE, Auerbach M, Avner JR, Daswani D, Khine H. Comparison of Glidescope videolaryngoscopy to virect laryngoscopy for intubation of a pediatric simulator by novice physicians. Emerg Med Int 2013;2013:407547.

9. Shin DH, Han SK, Choi PC, Sim MS, Lee JH, Park SO. Tracheal intubation during chest compressions performed by qualified emergency physicians unfamiliar with the Pentax-Airwayscope. Eur J Emerg Med 2013;20:187-92.

10. Malik MA, Hassett P, Carney J, Higgins BD, Harte BH, Laffey JG. A comparison of the Glidescope, Pentax AWS, and Macintosh laryngoscopes when used by novice personnel: a manikin study. Can J Anaesth 2009;56:802-11.

11. McElwain J, Malik MA, Harte BH, Flynn NM, Laffey JG. Comparison of the C-MAC videolaryngoscope with the Macintosh, Glidescope, and Airtraq laryngoscopes in easy and difficult laryngoscopy scenarios in manikins. Anaesthesia 2010;65:483-9.

12. Kim HJ, Chung SP, Park IC, Cho J, Lee HS, Park YS. Comparison of the GlideScope video laryngoscope and Macintosh laryngoscope in simulated tracheal intubation scenarios. Emerg Med J 2008;25:279-82.

13. Kabrhel C, Thomsen TW, Setnik GS, Walls RM. Videos in clinical medicine: orotracheal intubation. N Engl J Med 2007;356: e15. 